Esta revista forma parte del acervo de la Biblioteca Jurídica Virtual del Instituto de Investigaciones Jurídicas de la UNAM

\title{
RESTRICCIONES DE ACCESO A LA INFORMACIÓN CONTENIDA EN LOS REGISTROS DE UNA INVESTIGACIÓN PENAL. COMENTARIO AL ARTÍCULO 218 DEL CÓDIGO NACIONAL DE PROCEDIMIENTOS PENALES \\ $\bullet \circ$
}

\author{
Moisés Israel Flores Pacheco*
}

\section{INTRODUCCIÓN}

En este trabajo se pretende hacer una valoración de dos restricciones que generan las autoridades ministeriales encargadas de la procuración de justicia para tener acceso a los registros relacionados con una investigación de tipo penal y, posteriormente, confrontar dichas restricciones con el derecho humano de acceso a la información. Con base en lo anterior, en el segundo apartado se realiza un análisis concreto y particular del artículo 218 del Código Nacional de Procedimientos Penales (CNPP), en donde se plantea la cuestión y se exponen algunos antecedentes. También se estudian: $a$ ) la clasificación absoluta de reserva de todos los registros de investigación, y b) el plazo para tener acceso a la versión pública de una resolución de no ejercicio de la acción penal. Finalmente, se evalúan las restricciones existentes en ese artículo normativo y su proporcionalidad a la luz del principio de máxima publicidad y excepcionalidad de la reserva de información.

La relevancia del tema radica en que la procuración de justicia es una actividad de interés público para el desarrollo de la vida democrática nacional. En este sentido, una investigación criminal puede ser de gran in-

Maestro en derecho constitucional por la Universidad de Castilla-La Mancha. Cuenta con una especialidad en derechos humanos por la Universidad de Castilla-La Mancha y la Comisión Nacional de los Derechos Humanos (CNDH); es licenciado en derecho por la UNAM. Actualmente es estudiante de la maestría en derecho en la UNAM, mifp11@ hotmail.com.

Fecha de recepción: 04 de febrero de 2018.

Fecha de dictamen: 28 de febrero de 2018. 
Esta revista forma parte del acervo de la Biblioteca Jurídica Virtual del Instituto de Investigaciones Jurídicas de la UNAM

terés debido a que sus resultados podrían generar información de alto impacto en la esfera pública.

\section{Planteamiento de la Cuestión: las investigaciones penales SON INFORMACIÓN DE INTERÉS PÚBLICO}

94 En la actualidad, el derecho a la información va más allá de ser una manifestación de la libertad de expresión. Para María Alicia Junco (2003), engloba el deber del Estado de informar a los gobernados y, concretamente, la facultad - de recibir información relacionada con la obtención, recepción y difusión de - noticias. De acuerdo con esto, el derecho a la información del ciudadano se refiere al derecho de la noticia. La noticia debe referirse a hechos relevantes cuyo conocimiento es importante para la opinión pública (Junco, 2003: 9-12). Por lo antes descrito, resulta relevante realizar el presente análisis, que tiene como supuesto inicial el que algunas investigaciones criminales son relevantes y generan la obligación de las autoridades de informar a la opinión pública.

La pertinencia del tema se relaciona con la necesidad de que los medios de comunicación den a conocer datos importantes sobre el avance de las investigaciones penales. Actualmente, es de sobra conocida la función social y política de los medios, pues contribuyen en la formación de la opinión y, como consecuencia, hacen de medio de control del gobierno (Escobar de la Serna, 1998: 34 y 35). Por ello, resulta vital que cualquier ciudadano, pero especialmente los medios de comunicación, puedan acceder a la información generada por las investigaciones penales relevantes para la vida pública.

Esa información, al ser generada por autoridades en ejercicio de sus funciones y con recursos públicos, es, desde luego, información gubernamental a la que todos los ciudadanos deberíamos tener acceso. No obstante, al ser investigaciones de tipo criminal, se actualiza la excepción que dicta que parte de esta información puede ser reservada por las autoridades para que no sea conocida por el público hasta pasado un lapso de tiempo y bajo ciertas modalidades, ya que exponer determinados datos de manera anticipada puede llevar al fracaso las investigaciones que persiguen delitos.

Es muy comprensible que las autoridades encargadas de investigar hechos ilícitos guarden sigilo y secrecía sobre sus actuaciones, pues no debe perderse de vista que, en muchos casos, el éxito de las investigaciones de este tipo depende de que sean oportunas y discretamente con- 
Esta revista forma parte del acervo de la Biblioteca Jurídica Virtual del Instituto de Investigaciones Jurídicas de la UNAM

ducidas, a fin de que no se destruyan los indicios del delito y se evadan responsabilidades. Sin embargo, algunas investigaciones penales demandan un conocimiento público cuando se relacionan con hechos relevantes para la vida nacional, como puede ser la persecución de delitos de corrupción o de delincuencia organizada, y exigen que las autoridades rindan cuentas de manera constante sobre los avances que esas investigaciones presentan.

A causa de ello, las restricciones del derecho a la información no deben ser confundidas con la cultura del secreto. El secreto ha sido visto por Weber como parte de la cultura burocrática, en donde los gobiernos son proclives a excluir la publicidad para mantener su poder e influencia. La cultura del secreto por parte de los gobiernos facilita la opacidad y tiene un efecto dañino en la vida pública, porque con ella se ocultan los errores de los funcionarios, su negligencia y, peor aún, genera suspicacia por parte de los gobernados (Guerrero, 2008: 20-22). El secreto se mueve en el área de la discrecionalidad; en cambio, las restricciones al derecho de acceso a la información sólo pueden estar en el ámbito de la legalidad.

Destaca la resolución de la Suprema Corte de Justicia de la Nación (SCJN) en relación con la investigación del Caso Aguas Blancas en 1995, pues dio una nueva interpretación al derecho constitucional de acceso a la información al igualarlo con el derecho a la verdad, argumentando que las autoridades no pueden dar información falsa o manipulada, pero tampoco incompleta sobre los hechos ocurridos en esa trágica matanza (López Ayllón, 2016: 6).

Respecto al derecho de la información, existe una inquietud constante debido a que, a pesar de su reconocimiento, aún debe ser adecuado y efectivamente regulado. El reconocimiento sería el primer paso, pero el segundo recae en su integración a través de un marco jurídico que encuadre de manera eficaz los conceptos y sujetos intervinientes en esa relación (Junco, 2003: 52). Es por ello que el marco legal debe ser claro y adecuado para ajustarse a las necesidades de la sociedad que desea ser informada.

En ese sentido, es importante el análisis del artículo 218 del CNPP, que decreta una "reserva de los actos de investigación" y se aparta del marco general señalado por las leyes de acceso a la información y, más importante aún, se aparta de los principios constitucionales que regulan ese derecho.

Previo al análisis de las restricciones de dicho artículo, es pertinente puntualizar algunos antecedentes que proporcionen herramientas para construir dicho análisis. 
Esta revista forma parte del acervo de la Biblioteca Jurídica Virtual del Instituto de Investigaciones Jurídicas de la UNAM

En primer lugar, destaca la regulación constitucional del derecho de acceso a la información pública por ciertas bases, mediante reforma publicada el 20 de julio de 2007. Para armonizar las leyes ordinarias a esas bases constitucionales, el 23 de enero de 2009 se reformó el artículo 16 del Código Federal de Procedimiento Penales (CFPP), el cual regía las actuaciones de las autoridades penales en el sistema penal anterior al de tipo acusatorio. En él se agregaron dos disposiciones restrictivas para el acceso a la información contenida en averiguaciones previas (cuadro 1). Dichas disposiciones del CFPP tenían la intención de armonizar las normas del procedimiento de investigación penal con el derecho de acceso - a la información pública; sin embargo, tuvieron un efecto contrario, pues - resultaban discordantes y limitativas del acceso a la información pública que generaran las autoridades encargadas de la investigación de los delitos, debido a que fundaban reservas de información como un absoluto legal.

Como consecuencia, la Comisión Nacional de los Derechos Humanos $(\mathrm{CNDH})$ promovió la acción de inconstitucionalidad 26/2009 ante la SCJN para controvertir la validez de esas disposiciones, en razón de que, a su juicio, resultaban contrarias a las bases constitucionales de acceso a la información y a los principios de máxima publicidad y de excepcionalidad de las reservas de información. Como respuesta, la SCJN estudió en dicha acción si el artículo 16 del CFPP limitaba el derecho de acceso a la información pública. En primer lugar, revisó si la norma imponía a todas las averiguaciones previas una "estricta reserva", la cual se extendía sobre todos los documentos y objetos relacionados. En segundo lugar, estudió si el término mínimo que debía transcurrir para el otorgamiento de una versión pública de la resolución de no ejercicio de la acción penal era válido o resultaba desproporcionado.

En ambos casos, de los once ministros que integraban la Corte, la mayoría consideró que se actualizaba una causa de inconstitucionalidad, debido a que algunas disposiciones, al ser absolutas y carecer de proporcionalidad e idoneidad, limitaban el derecho de acceso a la información pública, por lo que debían ser declaradas como inválidas. No obstante, no se alcanzó la votación calificada de ocho votos para decretar la invalidez del citado precepto legal, y se determinó desestimar la acción de inconstitucionalidad. Con esa desestimación no se logró invalidar el artículo, el cual se mantuvo vigente hasta la entrada en vigor del Código Nacional de Procedimientos Penales en marzo de 2014. 
Esta revista forma parte del acervo de la Biblioteca Jurídica Virtual del Instituto de Investigaciones Jurídicas de la UNAM

\section{Contenido del artículo 2i8 del Código Nacional de Procedimientos Penales (CNPP)}

$\mathrm{Al}$ expedirse el CNPP que rige para el sistema procesal penal acusatorio, originalmente no se aplicaron disposiciones semejantes a las del artículo 16 del CFPP. Sólo se consideró la reserva de los registros de investigación durante la investigación inicial. No fue sino hasta junio de 2016 que se modificó el artículo 218 del CNPP para reformar el primer párrafo y adicionar un último, en donde, respectivamente, se clasifican como reservados todos los registros de investigación penal en todas y cada una de sus partes y, además, se señala un término mínimo de tres años para conceder únicamente la versión pública de la resolución de no ejercicio de la acción penal.

De modo que, con estas reformas, se homologó el artículo 218 del CNPP a las disposiciones del artículo 16 del CFPP, que regían en el anterior sistema, para mantener la estricta reserva de los registros contenidos en las investigaciones penales. En el cuadro 1 se comparan ambos textos.

\section{Cuadro i. Comparación del marco legal del acceso} A LOS REGISTROS DE LA INVESTIGACIÓN PENAL

\begin{tabular}{|c|c|}
\hline $\begin{array}{c}\text { Código Federal de Procedimientos } \\
\text { Penales }\end{array}$ & $\begin{array}{c}\text { Código Nacional de Procedimientos } \\
\text { Penales }\end{array}$ \\
\hline Artículo 16. [...] & $\begin{array}{l}\text { Artículo 218. Reserva de los actos de } \\
\text { investigación }\end{array}$ \\
\hline \multirow[t]{4}{*}{$\begin{array}{l}\text { REFORMADO, D.O.F. } 23 \text { DE ENE- } \\
\text { RO DE } 2009 \\
\text { Al expediente de averiguación previa } \\
\text { únicamente tendrán acceso el inculpa- } \\
\text { do, su defensor y la víctima u ofendido o } \\
\text { su representante legal. La averiguación } \\
\text { previa, así como todos los documentos, } \\
\text { independientemente de su contenido } \\
\text { o naturaleza, y los objetos, registros de } \\
\text { voz e imágenes o cosas que le estén } \\
\text { relacionados, son estrictamente reser- } \\
\text { vados }\end{array}$} & $\begin{array}{l}\text { REFORMADO, D.O.F. } 17 \text { DE JUNIO } \\
\text { DE } 2016 \\
\text { Los registros de la investigación, así } \\
\text { como todos los documentos, indepen- } \\
\text { dientemente de su contenido o natu- } \\
\text { raleza, los objetos, los registros de voz } \\
\text { e imágenes o cosas que le estén rela- } \\
\text { cionados, son estrictamente reservados, } \\
\text { por lo que únicamente las partes, po- } \\
\text { drán tener acceso a los mismos, con las } \\
\text { limitaciones establecidas en este Có- } \\
\text { digo y demás disposiciones aplicables. }\end{array}$ \\
\hline & {$[\ldots]$} \\
\hline & {$[\ldots]$} \\
\hline & \\
\hline
\end{tabular}


Esta revista forma parte del acervo de la Biblioteca Jurídica Virtual del Instituto de Investigaciones Jurídicas de la UNAM http://www.juridicas.unam.mx/ https://biblio.juridicas.unam.mx/bjv https://revistas.juridicas.unam.mx/

DOI: http://dx.doi.org/10.22201/iij.25940082e.2018.6.12468

MOISÉS ISRAEL FLORES PACHECO

98

\begin{tabular}{|c|c|}
\hline $\begin{array}{c}\text { Código Federal de Procedimientos } \\
\text { Penales }\end{array}$ & $\begin{array}{c}\text { Código Nacional de Procedimientos } \\
\text { Penales }\end{array}$ \\
\hline $\begin{array}{l}\text { ADICIONADO, D.O.F. } 23 \text { DE ENE- } \\
\text { RO DE } 2009 \\
\text { Para efectos de acceso a la información } \\
\text { pública gubernamental, únicamente de- } \\
\text { berá proporcionarse una versión pública } \\
\text { de la resolución de no ejercicio de la ac- } \\
\text { ción penal, siempre que haya transcu- } \\
\text { rrido un plazo igual al de prescripción } \\
\text { de los delitos de que se trate, de con- } \\
\text { formidad con lo dispuesto en el Código } \\
\text { Penal Federal, sin que pueda ser menor } \\
\text { de tres ni mayor de doce años, contado } \\
\text { a partir de que dicha resolución haya } \\
\text { quedado firme. }\end{array}$ & $\begin{array}{l}\text { ADICIONADO, D.O.F. } 17 \text { DE JUNIO } \\
\text { DE } 2016 \\
\text { Para efectos de acceso a la información } \\
\text { pública gubernamental, el Ministerio } \\
\text { Público únicamente deberá proporcio- } \\
\text { nar una versión pública de las determi- } \\
\text { naciones de no ejercicio de la acción } \\
\text { penal, archivo temporal o de aplicación } \\
\text { de un criterio de oportunidad, siempre } \\
\text { que haya transcurrido un plazo igual al } \\
\text { de prescripción de los delitos de que se } \\
\text { trate, de conformidad con lo dispuesto } \\
\text { en el Código Penal Federal o estatal } \\
\text { correspondiente, sin que pueda ser } \\
\text { menor de tres años, ni mayor de doce } \\
\text { años, contado a partir de que dicha de- } \\
\text { terminación haya quedado firme. }\end{array}$ \\
\hline \multicolumn{2}{|l|}{$[\ldots]$} \\
\hline \multicolumn{2}{|l|}{$[\ldots]$} \\
\hline \multicolumn{2}{|l|}{$[\ldots]$} \\
\hline \multicolumn{2}{|l|}{$[\ldots]$} \\
\hline \multicolumn{2}{|l|}{$[\ldots]$} \\
\hline$[\ldots]$ & \\
\hline
\end{tabular}

En este punto, es preciso analizar por separado ambas disposiciones del artículo 218 del CNPP, en los párrafos primero y último, a fin de facilitar la comprensión de las ideas expuestas.

\section{Clasificación absoluta de reserva de todos los registros de investigación}

En el primer párrafo, el artículo 218 del CNPP refiere que: 1) los registros de la investigación, así como todos los documentos, independientemente de su contenido o naturaleza, los objetos, los registros de voz, e imágenes o cosas que le estén relacionados, son estrictamente reservados, y 2) únicamente las partes podrán tener acceso a los mismos, bajo otras limitaciones establecidas en ese Código y demás disposiciones aplicables. 
Esta revista forma parte del acervo de la Biblioteca Jurídica Virtual del Instituto de Investigaciones Jurídicas de la UNAM

En esencia, en todos los casos la norma restringe el acceso de toda información contenida en los registros de investigación a todos aquellos que no sean parte de la investigación, situación que no atiende a los principios de proporcionalidad y razonabilidad, es decir, la norma genera un absoluto legal. Esta sería la primera discordancia existente entre este artículo y los mandatos del artículo 6o. de la Constitución Política de los Estados Unidos Mexicanos (CPEUM), en razón de que son una restricción del derecho de acceso a la información pública, y no se observa el principio de máxima publicidad.

Dicho artículo 6o., en su base A, fracción I, contiene tres principios constitucionales que son garantía del derecho a la información: 1) toda la información en posesión de cualquier autoridad, entidad, órgano y organismo de los poderes Ejecutivo, Legislativo y Judicial, órganos autónomos, partidos políticos, fideicomisos y fondos públicos, así como de cualquier persona física, moral o sindicato que reciba y ejerza recursos públicos o realice actos de autoridad en el ámbito federal, estatal y municipal, es pública; 2) dicha información sólo podrá ser reservada temporalmente por razones de interés público y seguridad nacional, en los términos que fijen las leyes, y 3) en la interpretación de este derecho deberá prevalecer el principio de máxima publicidad.

En cambio, la norma legal clasifica como reservados de manera absoluta todos los registros de investigación, en todas y cada una de sus partes, independientemente de su contenido o naturaleza. Es decir, que aun sin existir expedientes, y de manera anticipada, por disposición legal tales datos están reservados, sin que las autoridades deban justificar esa necesidad de reserva en cada caso concreto. Como consecuencia, se viola el principio de máxima publicidad, el cual señala que toda información en poder de las autoridades es pública y sólo admite excepciones limitadas para reservar información en los términos que fijen las leyes. En este caso, la excepción de la reserva de información es la regla y no la excepción.

La información de las investigaciones criminales tiene un marco legal sui generis que la exentan de la observancia de las reglas generales de acceso a la información pública. Si bien es cierto que el artículo 218 del CNPP busca salvaguardar el sigilo necesario de toda investigación, así como los derechos e intereses de las partes, éstas restricciones sólo pueden darse al tenor de que lo establecen la CPEUM y la Ley General de Acceso a la Información Pública (LGAIP). Es válido señalar que la información contenida en las investigaciones criminales puede ser reservada debido a que el derecho de acceso a la información no es un derecho absoluto y admite limitaciones; sin embargo, esas reservas sólo pueden aplicarse siempre y 
Esta revista forma parte del acervo de la Biblioteca Jurídica Virtual del Instituto de Investigaciones Jurídicas de la UNAM

cuando un interés público así lo justifique en cada caso concreto, y no como una regla absoluta para todas las investigaciones.

La reserva de información no debería ser decretada legalmente de manera generalizada, como se hace en el texto del artículo 218 del CNPP. Sería injustificado que la norma reserve toda la información contenida en la averiguación previa de todos los casos. Esa medida carece de razonabilidad y de proporcionalidad, de manera que no superaría un test de constitucionalidad porque no atiende a cada caso concreto.

Para el ejercicio del derecho de acceso a la información, previsto en el artículo 6o. de la CPEUM, el Congreso de la Unión dispuso su reglamentación en la LGTAIP con la existencia de mecanismos y procedimientos de revisión expeditos que desarrollan y dan contenido a ese derecho humano. En ese sentido, se observan algunas discordancias entre la disposición analizada y el marco general de acceso a la información pública con las siguientes implicaciones:

1) La clasificación, de acuerdo con el artículo 100 de la LGTAIP, es el proceso mediante el cual el sujeto obligado determina que la información en su poder actualiza alguno de los supuestos de reserva o confidencialidad. En este caso, la clasificación no existe como proceso, sino como decreto, dado que está creada en la ley y no en el expediente, y es ordenada por el legislador y no determinada por el sujeto obligado.

2) La norma penal no genera un plazo específico del periodo de reserva; es decir, al tratarse de aquella información contenida en los registros de investigación, no se señala el plazo al que estará sujeta la reserva, por lo que puede ser entendida como permanente. En cambio, en el artículo 101 de la LGTAIP se dispone que el plazo de reserva se da hasta por un máximo de cinco años, prorrogable excepcionalmente hasta por otros cinco años.

3) La norma combatida tampoco permite la aplicación de la prueba de daño, por la cual el sujeto obligado deba justificar que la divulgación de la información represente un riesgo real, demostrable e identificable de perjuicio significativo al interés público o a la seguridad nacional; que el riesgo de perjuicio que supondría la divulgación supere el interés público general de que se difunda, y que la limitación se adecúe al principio de proporcionalidad y represente el medio menos restrictivo disponible para evitar el perjuicio (LGTAIP, artículo 104). Como se aprecia, las causales de reserva previstas en la ley no están exentas de las obligaciones de fundar 
Esta revista forma parte del acervo de la Biblioteca Jurídica Virtual del Instituto de Investigaciones Jurídicas de la UNAM

y motivar cada acto de autoridad, sino que la legalidad del acto se debe demostrar a través de la aplicación de la prueba de daño a la que hace referencia la LGTAIP. En cambio, la norma penal exenta a las autoridades investigadoras de esta carga en perjuicio del ciudadano, que no tienen que hacer la fundamentación y motivación de la mencionada reserva simplemente porque ya está ordenada en la ley.

4) Las autoridades encargadas de la investigación penal podrán aplicar de manera ilimitada excepciones al derecho de acceso a la información por la estricta reserva contenida en el artículo 218, sin que deban acreditar su procedencia. Esto se opondría al mandato contenido en el citado artículo 6o. constitucional que señala que la "información sólo podrá ser reservada temporalmente por razones de interés público y seguridad nacional, en los términos que fijen las leyes". La carga de la prueba para justificar toda negativa por actualizarse cualquiera de los supuestos de reserva previstos corresponde a los sujetos obligados, en atención al principio de máxima publicidad contenido en la fracción I, de la base A de dicho artículo 6o.; sin embargo, en este caso el sujeto obligado no necesita justificar la actualización de una causa de reserva, más allá de la disposición legal que ordena su carácter absoluto de reservada.

5) Asimismo, la clasificación de la información se lleva a cabo aun sin que exista materia para reservar, o previo a la existencia de los registros de investigación, aunque éstos ya son inaccesibles. De acuerdo con el artículo 106 de la LGTAIP, la clasificación de información sólo puede actualizarse en el momento en que se reciba una solicitud de acceso a la información, se determine mediante resolución de autoridad competente, o se generen versiones públicas para dar cumplimiento a las obligaciones de transparencia previstas en esa ley.

6) Por tal circunstancia, los documentos que integran los registros de investigación se encuentran clasificados totalmente, sin indicar la fecha de la clasificación, el fundamento legal ni, en su caso, el periodo de reserva (LGTAIP, artículo 107).

7) La reserva generada en el artículo 218 del CNPP es una reserva total, pues ninguna información contenida en investigaciones penales podría ser conocida por el público. En tanto que, de acuerdo con el artículo 111 de la LGTAIP, cuando un documento contenga partes o secciones reservadas o confidenciales, los sujetos obligados, para efectos de atender una solicitud de información, deberán 
Esta revista forma parte del acervo de la Biblioteca Jurídica Virtual del Instituto de Investigaciones Jurídicas de la UNAM

elaborar una versión pública en la que se testen las partes o secciones clasificadas, indicando su contenido de manera genérica, y fundando y motivando su clasificación. En este caso, ni siquiera podría haber lugar para tener acceso a versiones públicas de cierta información contenida en esas investigaciones.

Como puede apreciarse, la clasificación de información reservada contenida en la ley se realiza sin un análisis caso por caso, sin la aplicación de la prueba de daño y sin observar los lineamientos generales en materia de clasificación de la información reservada y confidencial o para

- la elaboración de versiones públicas, elementos que son de observancia - obligatoria para los sujetos obligados.

En este caso, lo que se cuestiona no es la limitante al derecho a la información, sino su falta de legitimidad al no dar una justificación de manera fundada y motivada en cada caso concreto, lo que se opone al principio de máxima publicidad, que constituye el principio interpretativo rector en materia de derecho al acceso a la información.

Es válido reservar los registros de investigación, pero no debería suceder en la forma y términos en que lo hace la legislación penal, porque, de esta manera, se atentaría contra el principio de acceso a la información pública. La información sólo es reservable hasta que se surte uno de los supuestos permitidos para ello en la ley, y bajo ciertas premisas que deben acreditar los sujetos obligados para justificar la reserva. No obstante, no se puede aceptar como válido que se restrinja de manera absoluta y generalizada toda la información, tal como sucede con el caso del artículo analizado.

El texto vigente de la norma no se limita a establecer la posibilidad de que los registros de investigación se clasifiquen o puedan clasificarse como "reservados" de acuerdo con las leyes de trasparencia, sino que impone una regla genérica, a priori y sin distinción. Una interpretación equivocada de la norma resultaría en una alteración de las reglas que la Constitución establece respecto a la publicidad de la información, documentos y expedientes públicos, en tanto que el artículo 2018 del CNPP dispone reservar los registros de investigación.

La Primera Sala de la SCJN, al resolver el amparo en revisión 173/2012, el 6 de febrero de 2013, determinó que toda la información contenida en la averiguación previa (del sistema penal anterior) no debía considerarse reservada sin contener criterios que permitieran determinar casuísticamente qué información debe reservarse; es decir, la limitación de acceso a la información pública debe vincularse objetivamente con la realización de una 
Esta revista forma parte del acervo de la Biblioteca Jurídica Virtual del Instituto de Investigaciones Jurídicas de la UNAM

prueba de daño. Esta prueba consiste en la facultad de la autoridad, quien posee la información solicitada, para ponderar y valorar mediante la debida fundamentación y motivación el proporcionarla o no, en tanto que su divulgación ponga en riesgo o pueda causar un perjuicio real al objetivo o principio que trata de salvaguardar y, de manera estricta, debe demostrarse que el perjuicio u objetivo resulta mayor que los beneficios que podrían lograrse con la difusión de la información. ${ }^{1}$

En ese mismo asunto, se determinó que el artículo 16, párrafos segundo y tercero del CFPP, no resultaba proporcional al no existir una adecuada ponderación entre los principios en juego, esto es, entre el derecho de acceso a la información pública y el fin y objeto que busca con su restricción, específicamente el interés público o general, inmerso en la función pública de investigación y persecución de los delitos. Dicho numeral no establecía cuáles eran las razones específicas de interés público que autorizaban a reservar toda la información contenida en las averiguaciones previas. Así, al establecerse el supuesto general de que toda la información contenida en la averiguación previa debía considerarse en reserva, se impedía que el órgano respectivo pudiera discernir su actuar, y fundar y motivar su determinación para considerar las condiciones en las que se encuentra o no reservada la información. ${ }^{2}$

\section{Plazo para tener acceso a la versión pública de una resolución de no ejercicio de la acción penal}

En el último párrafo del artículo 218 del CNPP, se determina que el plazo mínimo que debe transcurrir para el otorgamiento de una versión pública de la resolución de no ejercicio de la acción penal, no puede ser menor de tres ni mayor de doce años, contados a partir de que dicha resolución haya quedado firme. Esto limita el acceso a la versión pública del no ejercicio y no a los documentos que la integran.

1 De este asunto derivó la Tesis 1a. CCXVII/2013 (10a.), en el Semanario Judicial de la Federación y su Gaceta, Décima Época, t. 1, julio de 2013, p. 533, del rubro: "ACCESO A LA averiguación previa. El artículo i6, párrafos segundo, tercero y sexto, del Código Federal de Procedimientos Penales, transgrede el derecho humano de acceso a la INFORMACIÓN".

2 De este asunto derivó la Tesis la. CCXVI/2013 (10a.), en el Semanario Judicial de la Federación y su Gaceta, Décima Época, t. 1, julio de 2013, p. 552, del rubro: "Averiguación

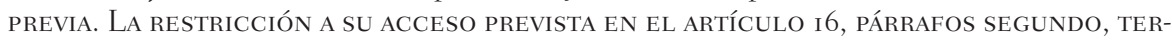
cero y sexto, del Código Federal de Procedimientos Penales, es desproporcional”. 
Esta revista forma parte del acervo de la Biblioteca Jurídica Virtual del Instituto de Investigaciones Jurídicas de la UNAM

Respecto a lo anterior, es preciso hacer dos observaciones. En primer lugar, carece de proporcionalidad establecer un periodo mínimo de tres años para poder acceder a la versión pública de la resolución por la cual el Ministerio Público determinó el no ejerció de la acción penal. En este sentido, si se ha extinguido la pretensión punitiva del Estado, se estima que también han desaparecido las posibles causas por las cuales se podría reservar la información, y por eso la norma carecería de racionalidad, al exigir un periodo mínimo de tres años para proporcionar una versión pública del no ejercicio de la acción penal, si las posibles causas de reserva han quedado extintas.

En tanto que las causas de reserva de información en el actual sistema de acceso a la información pública, de acuerdo con el artículo 101 de la LGTAIP, desaparecen, y la información se torna pública cuando se extingan las causas que dieron origen a su clasificación. Por tanto, si la autoridad ha determinado que no habrá persecución del delito por decretar el no ejercicio de la acción penal, la información contenida en esa determinación puede ser pública, dado que ya no hay motivos para mantener la reserva.

La segunda observación consiste en la falta de justificación para establecer que "únicamente" se dé acceso a la resolución de no ejercicio de la acción penal y no a los documentos que, en versión pública, se contengan en el expediente. Hay una falta de justificación para que los demás registros de investigación se resguarden por parte de la autoridad si la acción penal ha quedado sin ejercitarse. Se estaría ante el establecimiento implícito de una reserva de toda aquella información contenida en el expediente, pues sólo se permite el acceso a la resolución de no ejercicio en una versión pública.

De modo que, en este artículo, se encuentran dos restricciones. La primera es la cuestión relativa al tiempo que tiene que transcurrir para que se pueda entregar la resolución de no ejercicio de la acción penal. La segunda es la falta de racionalidad para que solamente se entregue una versión pública de la resolución del no ejercicio de la acción penal.

Lo dispuesto en el último párrafo del artículo 218 del CNPP es una estricta reserva, pues aun cuando se ha culminado la investigación penal por resolución de no ejercicio de la acción penal, el Ministerio Público debe reservar esa información cuando menos por tres años más y, sólo al término de este tiempo se proporcionará una versión pública del no ejercicio de la acción penal y no de todos los documentos que la integran.

En este caso, la restricción contenida en el último párrafo del CNPP no sería proporcional al no existir una adecuada ponderación entre los 
Esta revista forma parte del acervo de la Biblioteca Jurídica Virtual del Instituto de Investigaciones Jurídicas de la UNAM

principios en juego, esto es, entre el derecho de acceso a la información pública y el fin y objeto que busca con su restricción, específicamente el interés público en la investigación y persecución de los delitos.

El artículo analizado no establece cuáles son las razones de interés público que autorizan la reserva por un periodo mínimo de tres años a los registros de investigación que se hayan concluido por una resolución de no ejercicio de la acción penal, ni para no dar acceso a los registros de investigación.

\section{Consideraciones finales}

La reserva de la información contenida en las investigaciones penales es necesaria y justificada en aras de la adecuada procuración de justicia, pero ello no debe redundar en una negación absoluta del acceso a la información que las autoridades generen, sino en una restricción legítima que funde y motive de manera adecuada la reserva caso por caso, a fin de que el ciudadano tenga la certeza de que la negativa de información esté justificada y no se trate de un acto arbitrario.

En cambio, el actual artículo 218 del CNPP tiene dos restricciones que no parecen del todo compatibles con el marco constitucional que regula el derecho de acceso a la información, no porque establezca reservas, sino porque lo hace de manera absoluta y sin proporcionar una justificación adecuada y proporcional en cada caso, y sin legitimar la restricción apegándose a las reglas para la reserva de información pública.

En ese sentido, no basta con que una norma legal tenga un fin legítimo para establecer una restricción al derecho fundamental, sino que, además, debe ser proporcional; es decir, se debe demostrar al ciudadano que la divulgación de la información amenaza con causar un perjuicio sustancial a la procuración de justicia, y que la negativa de la información se basa en que se perjudica más al interés público con su divulgación que al derecho del ciudadano.

\section{Fuentes de INFORMACIÓN}

Escobar de la Serna, Luis, 1998, Derecho de la información, España, Dykinson.

Guerrero, Eduardo, 2008, La transparencia, México, Nostra Ediciones.

Junco, María Alicia, 2003, El derecho a la información: de la penumbra a la transparencia, México, Porrúa. 
Esta revista forma parte del acervo de la Biblioteca Jurídica Virtual del Instituto de Investigaciones Jurídicas de la UNAM

López Ayllón, Sergio, 2016, "El trayecto de la reforma constitucional: del derecho incierto al derecho a parte entera", en PEschard, Jacqueline (coord.), Hacia el Sistema Nacional de Transparencia, México, UNAM, Instituto de Investigaciones Jurídicas.

Marco jurídico

106

Constitución Política de los Estados Unidos Mexicanos (CPEUM), disponible en: www.diputados.gob.mx/LeyesBiblio/index.htm.

- Ley General de Transparencia y Acceso a la Información Pública (LGTAIP), disponible en: www.diputados.gob.mx/LeyesBiblio/pdf/LGTAIP.pdf .

Código Nacional de Procedimientos Penales (CNPP), disponible en: http:// www.diputados.gob.mx/LeyesBiblio/pdf/CNPP_170616.pdf.

Código Federal de Procedimientos Penales (CFPP), disponible en: https:// www.juridicas.unam.mx/legislacion/ordenamiento/codigo-federal-de-proce dimientos-penales. 